\title{
STUDI KRITIS TAFSIR MAFATIH AL-GHAIB
}

\author{
Oleh: Firdaus \\ ${ }^{1}$ Institut Agama Islam Muhammadiyah Sinjai, \\ Jl.Sultan Hasanuddin. No. 20 Balangnipa, Sinjai \\ E-mail:doktorfirdaus@gmail.com, Tlp:+628114188997
}

\begin{abstract}
Abstrak
Tulisan ini membahas tentang Mafatih al-Ghaib yang ditulis oleh seorang ulama terkenal, Imam Fakhr ad-Din ar-Razi. Secara gamblang tulisan ini menjelaskan seluk beluk pemikiran tafsirnya, yakni dimulai dari sumber tafsir, corak tafsir, demikian dengan metode tafsirnya, dilengkapi dengan pandangan-pandangan Ar-Razi terhadap ulum al-Qur'an. Hal ini penting dalam kajian tafsir khususnya pada tafsir dengan sumber bi al-ra'yi, mengingat betapa komprehensifnya ulasan yang disampaikan oleh ar-Razi dalam tafsir ini. Menjadi hal yang tidak bisa ditolerir jika produk tafsir dari masa ke masa tidak dikenal oleh para pegiat tafsir masa kini. Hal demikian tentu didasari oleh urgennya kedudukan tafsir yang terbilang klasik menjadi acuan pagi mufasir modern dalam menjelajahi setiap makna yang diinterpretasikan dari ayat-ayat-Nya. Demikianlah bahwa lahirnya studi tafsir mafatih al-Ghaib ini juga untuk mengisi ruang tersebut.
\end{abstract}

\section{Kata Kunci: Studi Kritis, Mafatih al-Ghaib}

\section{PENDAHULUAN}

Secara umum, metode tafsir al-Qur'an terbagi kepada empat macam, yaitu metode tahlily, maudhu'i, muqaran dan ijmaly. Keempat metode ini mewarnai seluruh karya tafsir, sejak dulu sampai sekarang. Metode tafsir tahlily merupakan metode tafsir paling tua. Para mufassir klasik menyusun kitab tafsir dengan menggunakan metode tersebut. Mereka menjelaskan ayat-ayat al-Qur'an berdasarkan urutannya dalam mushaf Usmani dan seluruh aspek di dalamnya, baik dari segi kosa kata, asbab al-nuzul, munasabah dan hal-hal yang berkaitan dengan teks atau kandungan ayat.

Di samping itu, ada tiga corak tafsir yang mempengaruhi para mufassir dalam menyusun kitab tafsir, yaitu al-ma'tsur, al-ra'yi dan al-isyariy. Boleh dikatakan bahwa seluruh kitab tafsir yang disusun oleh mufassir klasik adalah kitab tafsir al-Ma’tsur. Setelah ilmu pengetahuan berkembang dengan pesat dan para ulama telah menguasai berbagai disiplin ilmu, mereka menyusun kitab tafsir dengan lebih mengedepankan ra'yu dan diwarnai oleh latar belakang pendidikan mereka.

Salah satu kitab tafsir yang muncul dengan corak al-ra'yu dan diwarnai oleh berbagai ilmu pengetahuan adalah tafsir Mafâtih al-Ghaib atau tafsir al-Kabir. Kitab ini disusun oleh seorang mufassir yang sangat rasional dan menguasai berbagai disiplin ilmu pengetahuan, baik agama maupun umum, seperti ilmu kalam, ushul fiqhi, ilmu alam, astronomi, perbintangan dan agronomi. Ilmu-ilmu ini sangat berpengaruh kepadanya dalam menafsirkan ayat-ayat al-Qur'an. Untuk memahami lebih dalam kitab tafsir ini, makalah ini 
akan menguraikannya dengan mengacu pada pokok masalah, yaitu : Bagaimana profil dan manhaj kitab tafsir Mafâtih al-Ghaib karya al-Razi.

\section{PEMBAHASAN}

\section{A. Profil Ar-Razi}

\section{Riwayat Hidup Imam Ar-Razi}

Nama lengkap al-Razi adalah Muhammad bin 'Umar bin al-Husain bin al-Hasan bin 'Ali al-Timiy al-Bakariy al-Thabariy al-Ashl,1 dan memiliki nasab sampai kepada Abu Bakar Shiddiq ra. Beliau memiliki banyak julukan, di antaranya Abu Abdullah, Abu alMa'ali, Abu al-Fadhl, Ibn Khatib al-Ray2, al-Imam, Fakhr al-Din, al-Razi dan Syaikh alIslam. Gelaran-gelaran ini diberikan kepadanya karena beliau telah menguasai berbagai bidang ilmu pengetahuan, baik pengetahuan agama maupun umum. Ia lahir di kota Ray 3 pada tanggal 25 Ramadhan $544 \mathrm{H} / 543 \mathrm{H}$ dan wafat pada hari raya Idul fitri tahun $606 \mathrm{H}$ di kota Herat.4

Sejak kecil, al-Razi dididik oleh ayahnya, Khathib al-Ray. Dialah yang mula-mula mengajarinya ilmu keislaman, terutama ushul fiqhi. Setelah ia wafat, al-Razi belajar kepada al-Simnany kemudian pada al-Majd al-Jiliy (murid al-Gazali) tentang ilmu kalam dan hikmah dalam waktu yang cukup lama. Bahkan ia telah menguasai risalah teologi al-Syamil fi Ushul al-Din (karya Imam Haramain), al-Musthashfa (karya al-Gazali) dan al-Mu'tamad (karya Abu Hasan al-Bishri).5 Di samping itu, ia juga menaruh perhatian yang sangat besar terhadap kitab al-Mufashshal (karya al-Zamakhsyariy) dalam ilmu nahwu dan kitab al-Wajiz (karya al-Gazali) dalam ilmu fiqhi. Kedua kitab tersebut telah disyarahnya. Kemudian ia

1Muhammad al-Razi Fakhr al-Din, Tafsir al-Fakhr al-Razi, Juz I (t.tp: Dar al-Fikr, t.th) h. 3

2Orang yang bergelar dengan al-Razi banyak, di antaranya adalah Abu bakar Muhammad bin Zakaria al-Razi (seorang Dokter dan Filosof terkenal, w. 311/313 H); Abu al-Husain Ahmad bin Faris bin Zakaria alRazi (Ahli Bahasa dan Fiqih, w. 360 H); Quthb al-Din al-Razi (Pengarang kitab risalah al-Quthbiah, w. 766 H); tiga ulama Andalusi (semuanya dikenal dengan al-Razi dan semuanya adalah sejarawan, yaitu Muhammad bin Musa bin Basyir bin Jamal bin Laqith al-Kinaniy, w. 864. H; Ahmad bin Muhammad, 274 H-344H; dan Isa bin Ahmad bin Muhammad); Abu Basyar Muhammad bin Ahmad al-Razi al-Daulabiy (Ahli Hadis, w. 320 H); Abu Zakaria bin Mu'az al-Razi (Ahli Tarekat, w. 258 H); dan Abu al-Haytsam al-Razi (Ahli Bahasa Arab, w. 266H).

3Ray adalah sebuah kota yang terletak di wilayah bagian dari daerah-daerah terkenal di negeri al-Dailan (kini Afghanistan), letaknya dekat dengan wilayah Badghis, Ghot dan Farah. Untuk lebih jelasnya, lihat peta provinsi-provinsi di Afghanistan. Selanjutnya, penisbahan al-Razi sebagai julukan yang diberikan kepadanya merupakan term yang dimodifikasi dari kata al-Ray. Sebagaimana pula kota Marwa dimodifikasi menjadi Marwazi. Lihat Muhammad Hasan al-Umariy, al-Imam Fakhr al-Din al-Raziy (t.tp: tp, t.th) h. 18

4Muhammad Ibrahim 'Abd al-Rahman, Manhaj al-Fakhral-Razy fiy al-Tafsir (Nashr: alShadr Likhidmati ath-Thaba'ah, 1989), h. 25. Lihat juga, Muhammad al-Sayyid Jibril, Madkhal ila Manahij al-Mufassirin (Kairo: t.p, t.th), h. 114

5Ibid (Jibril). 
juga mempelajari dua buah kitab karya Abdul Qahir dalam ilmu balaghah dan meringkasnya dalam sebuah kitab yang diberi judul: Nihayat al-Ijaz fi Dirayat al-Ijaz.

Selanjutnya, al-Razi mempelajari ilmu filsafat dari buku-buku Aristoteles dan Plato serta filosof-filosof muslim, seperti Ibnu Sina, al-Farabi dan Abu al-Barakat al-Baghdadi.6 Dalam bidang ini, ia memberi syarah kitab al-Isyarat karya Ibnu Sina, kemudian menyusun buku dalam ilmu kedokteran dengan judul Syarh al-Kulliat li al-Qanun.

Setelah menguasai berbagai disiplin ilmu pengetahuan seperti ilmu kalam, filsafat, ushul fiqhi dan ilmu-ilmu keislaman lainnya, ia melakukan rihlah ke beberapa daerah sekitar Ray, seperti Khawarizm. Di tempat ini, ia berdialog dengan tokoh-tokoh masyarakat dan penduduk setempat tentang persoalan mazhab dan akidah. Penduduk setempat tidak dapat menerima pendapat al-Razi yang sangat rasional, sehingga ia diusir dari tempat tersebut. Kemudian ia menuju Transoksiana. Di tempat ini pula, penduduk tidak bisa menerima pandangannya sehingga perdebatan yang seru terjadi lagi. Akhirnya, al-Razi memutuskan untuk kembali ke al-Ray.

Setibanya di tempat kelahirannya, al-Razi menghadap kepada Sultan Syihab al-Din al-Ghouri kemudian menghadap kepada Sultan Ala' al-Din Muhammad bin Tuksy Khawarizm dan mendapat sambutan yang hangat serta kedudukan yang tinggi.7 Hubungannya dengan penguasa setempat sangat harmonis, namun tidak mempengaruhi kegiatan intelektualnya. Ia terus bergelut dengan berbagai ilmu pengetahuan dan menghasilkan sejumlah karya dalam berbagai bidang ilmu pengetahuan.

Di Ray, al-Razi tinggal bersama dengan seorang dokter terkenal memiliki harta kekayaan yang cukup besar. Sang dokter memiliki dua puteri dan ketika dokter sakit keras dan merasa ajalnya telah dekat, ia segera menikahkan kedua puterinya dengan kedua putera al-Razi. Harta kekayaannya dititipkan pada al-Razi untuk dipelihara dan dimanfaatkan, sehingga dapat memenuhi kebutuhan hidupnya. 8

Kemampuan al-Razi menguasai berbagai disiplin ilmu sangat menakjubkan, melihat situasi dan kondisi dunia Islam saat itu sedang mengalami disintegrasi politik dan labilnya keamanan. Dalam hal ini, Sayyid Husain Nashr mengatakan bahwa jarang sekali seorang pemikir Islam dapat menguasai berbagai disiplin ilmu seperti yang dialami oleh al-Razi. Karena pada saat itu, biasanya para mutakallimin sunni dan ahli fikihnya telah menjauhkan diri dari cabang-cabang pengetahuan di luar bidang agama.9

6Muhammad Ibrahim Abd al-Rahman, op.cit.,h. 26.

7Al-Umary, op.cit., h. 20.

8Ibid. Lihat Muhammad Ibrahim 'Abd al-Rahman, op.cit., h.27.

9Sayyid Husain Nashr, Fakhr al-Din al-Razi, dalam M.M. Syarif, "a History of Muslim Philosophy (td), h. 54. 
Al-Razi memiliki keunggulan dalam bidang ilmu agama maupun umum dibanding para ilmuan pada masanya. Ia juga dikenal ahli debat, selalu mengungguli lawan-lawannya dengan argumen-argumen yang logis dan bahasa yang fasih. Kritikan-kritikannya tidak hanya ditujukan kepada ilmuan pada masanya tapi juga imam-imam terdahulu, seperti Imam Asy'ary, Ibnu Faruq, Qadhi Abu Bakar dan Imam Haramain. Meskipun dalam fiqhi, ia bermazhab Syafi'iy dan Asy'ariy dalam ilmu kalam.

Menjelang akhir hayatnya, al-Razi mengalami skeptis terhadap kemampuan rasio sebagaimana yang telah dialami juga oleh al-Gazali.10 Kepercayaannya kepada kemampuan akal mulai menurun dan tergoncang. Karena itu, ia berpesan kepada salah seorang muridnya yang setia, yaitu Ibrahim bin Abu Bakar al-Asfahani agar di dalam mencari kebenaran tidak hanya melalui perdebatan akal semata, tetapi yang terpenting adalah menelusuri kandungan al-Qur'an. Delapan bulan setelah berpesan, ia sakit keras dan menghembuskan nafasnya yang terakhir dalam usia 57 tahun.

Berita kematian al-Razi sangat kontroversial, ada yang mengatakan bahwa ia meninggal karena diracun oleh lawan-lawannya dari kelompok Karamiyah, dan ada yang mengatakan bahwa ia meninggal secara wajar akibat sakit keras yang dideritanya. Kontroversial ini berlanjut terus tanpa ada penyelesaiannya.

\section{Guru, Murid, dan Karya-Karya Ar-Razi}

Guru-guru al-Razi antara lain adalah Dhiya'u al-Din Umar bin al-Hasan Khathib alRay (ayah al-Razi), Muhiy al-Sunnah Abi Muhammad al-Baghawiy, Abu al-Qasim alAushariy (murid Imam Haramain), Al-Kamal al-Simnaniy, dan Al-Majd al-Jiliy.

Adapun murid-murid al-Razi, antara lain Ibrahim bin Ali bin Muhammad al-Quthub al-Salamiy al-Maghribiy, Qadhi al-Qudhat Ahmad bin al-Khalil bin 'Isa al-Barmakiy, Abd al-Hamid bin Isa bin 'Amwaiyh bin Yunus bin Khalil al-Khasru Syahiy, Ibrahim bin Abi Bakr bin 'Ali al-Ashbahaniy, Syarf al-Din bin 'Unayn 'Abu al-Mahasin Muhammad bin Nashir bin Ghalib, Zayn al-Din al-Kasysyi, Taj al-Din al-Armawiy dan Ahmad bin Muhammad bin Abi al-Hazm al-Makky Najm al-Din al-Mahzumy al-Qamuly.

Sedangkan karya-karyanya, antara lain Mafatih al-Ghaib (tafsir al-Kabir), Ikhtisar Dalail alI'jaz, Asas al-Taqdis, Asrar al-Tanzil wa Anwar al-Ta'wil, I'tiqadat Faeq al-Muslimin wa alMusyrikin, Al-Bayan wa al-Burhan fi al-Rad 'Ala Ahl al-Zayan wa al-Thughyan, Al-Tanbih ala Ba'dhi al-Asrar al-Maudhi'ah fi Ba'dhi Suwar al-Qur'an, Syifa' al-Ayyi' wa al-Ikhtilaf, Al-Thariq fi al-Jadl, Ashamah al-Anbiya', Fadha'il al-Shahabah, Lubab al-Isyarat dan masih banyak lagi karya-

10Skeptis yang dialami oleh al-Razi mengarahkannya kepada asketik atau gnostik. Namun dalam hal ini, ia berbeda dengan al-Gazali. Al-Gazali lebih tulus (ashdaq) dari pada dia, karena tampaknya al-Razi tidak sesuai dengan keadaan seorang sufi. Ia mati dengan meninggalkan kekayaan yang banyak dan hubungannya dengan raja-raja tidak diputuskan (tetap harmonis), sementara al-Gazali tidak demikian. Lebih lanjut dapat dilihat pada, al-Umary, op.cit., h. 87) 
karyanya yang lain, bahkan mencapai 200 judul, namun yang sempat dicetak dan sampai ke tangan kita hanya sedikit.11

\section{Manhaj Tafsir Mafâtih al-Ghaib (al-Kabir)}

Kitab tafsir ini mempunyai tiga nama, yaitu tafsir al-Kabir, tafsir al-Razi dan Mafâtih al-Ghaib. Penamaan kitab tafsir al-Kabir didasarkan pada kebesarannya, sedangkan nama al-Razi disandarkan pada julukan pengarangnya dan mafatih al-Ghaib diilhami oleh و عنده مفاتح الغيب لا يعلمها الا اله Penyebutan ketiga nama tersebut sama-sama populer di kalangan umat Islam. Menurut sejarah, tafsir ini disusun oleh al-Razi setelah menguasai berbagai disiplin ilmu, seperti ilmu kalam dan logika. Kitab tafsir ini menjadi lebih populer lagi setelah adanya usaha dari ulama untuk melakukan kajian dari berbagai aspek yang terdapat di dalamnya.

Sebagaimana lazimnya penulisan sebuah kitab tafsir, al-Razi juga menggunakan metode penulisan sebagaimana yang dilakukan oleh penulis tafsir lainnya. Tafsir al-Razi yang beredar sekarang ini terdiri dari dua belas jilid. Jilid pertama memuat mukaddimah yang berisi beberapa penjelasan tentang penyusunan kitab tafsir ini dan riwayat hidup alRazi yang ditulis oleh al-Farrakh. Dalam jilid ini pula, al-Razi menguraikan penafsiran surat al-fatihah dan sebagian surat al-Baqarah.

Ada perbedaan di kalangan ulama mengenai penulisan kitab ini. Al-Dzahabi mengemukakan pendapat Ibnu Hajar al-Asqalani bahwa yang menyempurnakan tafsir Fakhr al-Din al-Razi adalah Ahmad bin Muhammad bin Abi al-Hazm Makkiy Najm al-Din alMahzumi al-Qamuli (w. 727 H). Sedangkan Musthafa Ibnu Abdullah (pengarang kitab Kasyf al-Zunun) berkata bahwa Syihab al-Din bin Khalil al-Khufi al-Dimasyqi (w. 639) yang melanjutkan penulisan kitab tafsir al-razi, kemudian al-Syaikh Najm al-Din Ahmad bin Muhammad al-Qamuli (w. 727 H)yang menyelesaikannya. 12

Berdasarkan pendapat ulama di atas dapat disimpulkan bahwa sebenarnya al-Razi tidak sempat menyelesaikan tulisannya secara lengkap. Ia hanya mampu menyelesaikannya sampai surat al-Anbiya'. Kemudian dilanjutkan oleh muridnya yang setia, yaitu Najm al-Din al-Qamuli. Karena sang murid betul-betul telah menguasai metodologi dan idiom gurunya sedemikian tepatnya sehingga gaya penulisan keduanya dalam kitab tafsir al-Kabir tersebut tidak dapat dibedakan. 13

\section{Metode Tafsir Ar-Razi}

Al-Razi menggunakan metode tahliliy dalam menyusun kitab tafsirnya. Langkahlangkah yang ditempuh oleh Beliau adalah sebagai berikut:

11Al-Umary, op.cit., h. 209.

12Muhammad Husayn al-Dzahabi, al-Tafsir wa al-Mufassirun, Jilid I (Beirut: Dar alQalam, t.th), h. 291

13Ensiklopedi Tematis Dunia Islam, Jil.I(ttp: PT Ichtiar Baru Van Hoeve, tth), h. 175-176. 
a. Menyebutkan jumlah ayat dalam setiap surat dan jumlah ayat makkiyah dan madaniyah.

b. Menafsirkan ayat berdasarkan urutan Mushaf Usmani.

c. Setelah mengemukakan ayat yang akan dijelaskan, ia menyebut kata fi al-ayat masâ'il, lalu memasuki penafsiran ayat dengan merincinya kepada beberapa masalah.

d. Menafsirkan al-Qur'an dengan pendekatan beberapa ilmu yang telah dikuasainya, seperti ilmu bahasa, ushul, fiqhi, qira'at, asbab al-nuzul, syair dan sedikit hadis.

\section{Corak Tafsir}

Tafsir al-Razi diwarnai dengan corak teologis-filosofis dan fiqh. Ayat-ayat yang bernuansa teologis ia gunakan visi kalam Asy'ari. Dan ayat-ayat fiqhi, ia terapkan elaborasi fiqhi Syafi'i.

\section{Sumber Tafsir}

Tafsir al-Razi memuat pandangan-pandangan para mufassir, seperti Ibnu Abbas, Ibnu al-Kalabiy, Mujahid, Qatadah, al-Saddiy, dan sa'id bin Jubair. Dan dalam bidang bahasa, al-Razi menukil pendapat dari perawi-perawi besar, seperti al-Ashamiy, Abi Ubaidah, dan dari golongan ulama seperti al-Farra, al-Zujjaj, dan al-Mubarrad. Sedangkan dalam bidang tafsir beliau menukil pendapat Muqatil bin Sulaiman al-Marwaziy, Abu Ishak al-Tsa'labiy, Abu al-Hasan 'Ali bin Ahmad al-Wahidi, Ibnu Qutaibah, Muhammad bin Jarir al-Thabariy, Abu Bakar al-Baqillaniy, Ibnu Furak (guru al-Razi), al-Quffal al-Syasyi alkabir, dan Ibnu Urfah.

Adapun Ulama Mu'tazilah yang dinukil pendapatnya oleh al-Razi, diantaranya Abu Muslim al-Isfahaniy, al-Qadiy 'Abd al-Jabbar, al-Zamakhsyari. Adapun pandangan alZamakhsyari, al-Razi menukilnya dalam rangka menolaknya dan membatalkan kehujjahannya. Pendapat-pendapat para ulama tersebut memperkaya kitab tafsir al-Razi.

\section{B. Sikap Ar-Razi terhadap Hal-hal yang Berkaitan dengan Ulum al-Qur'an}

\section{Qira'at}

Al-Razi mengemukakan beberapa qiraat dalam suatu ayat al-Qur'an, lalu menjelaskan makna setiap qiraat tersebut. Menurut al-Razi, qiraat yang dapat diperpegangi adalah qiraat mutawatir dan qiraat yang telah dikemukakan oleh sahabat. Jika ada qiraat yang bertentangan dengan qiraat yang mutawatir, maka qiraat tersebut tertolak. Beliau juga terkadang berhujjah dengan qiraat yang 
dikemukakan oleh ahli nahwu, bahkan sesekali menerima qiraat syadz jika sesuai dan dapat memperkuat penafsirannya terhadap suatu ayat.14

\section{Munasabah}

Semua ayat dan surat dalam al-Qur'an memiliki munasabah atau hubungan yang serasi. Keserasian susunan itu merupakan keindahan dan kemu'jizatan al-Qur'an. Al-Razi menamakan keserasian susunan itu dengan al-Nazhm. Tampaknya, ia melihat bahwa munasabah tidak hanya terdapat antara ayat dengan ayat, tapi juga akhir surat dengan awal surat berikutnya dan antara satu surat dengan surat lain. Contoh munasabah ayat dengan ayat: اذ قالوا لنبي لهم ابعث لنا (QS. Al-Baqarah: 246), menurut al-Razi, ayat ini berhubungan dengan ayat sebelumnya, di mana ayat sebelumnya, Allah memerintahkan untuk berperang, sebagaimana firman-Nya وقاتلوا في سبيل اله (QS. al-Baqarah: 190), setelah itu Allah memerintahkan untuk berinfaq (lihat QS. al-Baqarah: 195); contoh munasabah antara akhir surat dengan awal surat berikutnya, akhir surat al-“Adiyat: ان ربهم بهم يو مئذ لخبير (QS. al-

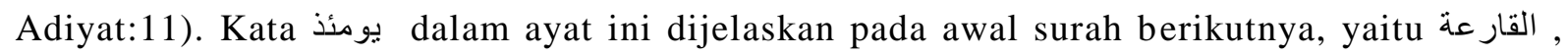
yang berarti hari kiamat. Kemudian contoh munasabat antara suatu surat dengan surat yang lain, adalah surat al-Ashr dengan al-Humazah. Dalam surat al-Ashr dijelaskan bahwa ada 3 golongan yang tidak merugi, sebaliknya dalam surat al-Humazah ada 3 golongan yang mendapat azab.

Di samping itu, beliau sangat memperhatikan detail-detail susunan al-Qur'an. Maksudnya, jarak antara satu surat dengan surat yang lain -yang diantarai oleh beberapa surat- pada hakekatnya mempunyai munasabat. Misalnya, beberapa surat mulai dari surat $a l$ Duha sampai surat al-Kautsar memiliki hubungan. Menurut beliau, surat al-Kautsar menyempurnakan surat-surat sebelumnya dan merupakan awal dari surat-surat sesudahnya. Alasan beliau adalah bahwa Allah menjadikan surat al-Dhuha sebagai pujian kepada Nabi Muhammad SAW, dan menginformasikan mengenai keadaannya. Kemudian menyebutkan tiga ayat pada awal surat yang berkaitan dengan kenabiannya, yaitu: pertama, firman Allah

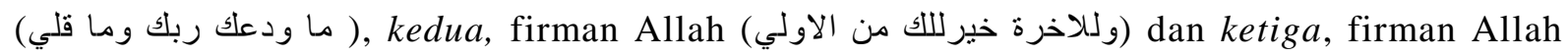
(ولسوف يعطيك فترضي). Lalu menyebutkan ayat yang berkaitan dengan kondisi yang berhubungan dengan masalah dunia, yaitu firman-Nya:

$$
\text { (الم يجدك يتيما فاوي ووجدك ضالا فهدي ووجدك عائلا فاغني) }
$$

\section{Sebab Nuzul}

Asbab nuzul adalah salah satu ilmu al-Qur'an yang mendapat perhatian besar dari alRazi. Ia menilai bahwa asbab nuzul merupakan hal yang sangat penting dalam memahami

14Al-Umary, op.cit.,h.125. Lihat Muhammad Ibrahim, op.cit.,h. 152. 
ayat-ayat al-Qur'an. Namun tidak selamanya ia dapat diperpedomani karena ada ayat yang memiliki sebab nuzul, namun lafaz ayat tersebut berlaku umum . Oleh karena itu, salah satu kaedah yang diperpegangi oleh al-Razi adalah: العبرة بعموم اللفظ لا بخصو ص السبب. Seperti surat al-Ma'idah ayat: 38 yaitu: ... و السارق و السارقة فاقطعو ا أبديهما. Menurut asbab nuzulnya, ayat ini menunjuk kepada sebuah kasus yang ditujukan kepada seseorang yang telah mencuri pada waktu itu, sehingga jika dipahami hanya berdasarkan asbab nuzulnya, maka ayat ini hanya berlaku pada orang tersebut dan waktu tertentu saja. Oleh karena itu, kaedah di atas harus digunakan dalam memahami ayat tersebut. Di samping itu, ada ayat yang memiliki beberapa sebab. Dalam hal ini, al-Razi mengemukakan semuanya dan banyak menyandarkannya kepada sahabat dan tabi'in. Namun terkadang, ia menguatkan riwayat yang satu dan melemahkan yang lainnya dengan mengemukakan sanadnya agar dapat memperkuat pendapat dan alasannya.15. Beliau banyak menyebutkan asbab al-nuzul terutama dalam urusan sahabat dan kafir quraisy. Ia menginginkan agar setiap memahami ayat-ayat al-Qur'an berdasarkan dengan asbab al-nuzul. Apalagi ayat-ayat yang tidak memiliki sebab nuzul jumlahnya sedikit.

\section{An-Nasikh dan Al-Mansukh}

Menurut al-Razi, pada dasarnya tidak ada naskh dalam al-Qur'an. Beliau melemahkan pendapat ulama yang mendukung adanya naskh, dengan alasan yang kuat dan bukti-bukti yang pasti, seperti ayat al-Qur'a yang berbunyi: اتبع ما احي اليك من ربك (QS. AlAn'am: 106).

\section{Al-Muhkam dan Al-Mutasyabih}

Al-Razi mengakui bahwa al-Qur'an memuat ayat-ayat muhkam dan mutasyabih. Bahkan ayat-ayat muhkam dapat menyingkap ayat-ayat yang mutasyabih. Ia juga setuju jika ada ulama yang mengatakan bahwa semua ayat al-Qur'an adalah muhkam atau mutasyabih 16.

\section{Sikap al-Razi terhadap Hadis}

Hadis-hadis yang terdapat dalam kitab tafsir Al-Razi jumlahnya sedikit, terbatas dalam persoalan fiqhi yang dikemukakan oleh para fuqaha. Sedangkan keutamaan surat, diantaranya surat al-Ikhlas, yang dinilai oleh sebagaian ulama sebagai hadis dha'if bahkan maudhu'. Beliau tidak selektif dalam mengemukakan hadis dan banyak menukil dari alZamakhsyari dan al-Tsa'labi.

15Muhammad Ibrahim, op.cit., h.156.

16Ibid., h. 159. 


\section{Sikap al-Razi terhadap Syair}

Salah satu kelebihan al-Razi dibandingkan dengan mufassir lainnya adalah menafsirkan al-Qur'an berdasarkan syair. Al-Razi mengemukakan syair jika dibutuhkan, baik dalam makna lughawi, nahwu atau balagah. Dan terkadang beliau mengemukakan baitbait syair untuk menjelaskan makna adab, akhlak dan agama. Sebuah contoh yang dikemukakan al-Razi untuk memberikan dukungan syair atas makna lughawi, ketika beliau menafsirkan firman Allah: يعلمون الناس السحر (QS. Al-Baqarah:102). Al-Razi berkata, masalah pertama dalam pembahasan ini adalah bahasa, lalu mengatakan, ahli bahasa menyebutkan bahwa pada dasarnya ungkapan, baik halus atau tidak jelas sebabnya, sihir dinisbahkan kepada makanan dan kehalusan. Sebagaimana syair yang dikemukakan Lubaid: . Terdapat dua pandangan dalam hal ini yaitu: pertama, bahwa sihir yang dimaksud adalah penipuan. Kedua, memberi makan artinya penyembunyian.17

Lebih lanjut al-Razi mengemukakan bahwa untuk memahami makna bahasa disesuaikan dengan hal yang sebenarnya, yaitu dengan mengambil dari hadis dan syair. Dan kadangkala beliau mengambil dari perkataan orang Arab. 18

Al-Razi mengungkapkan syair untuk menunjukkan keadaan jiwa, sebagaimana dalam penafsirannya terhadap ayat: والذين كسبوا السيات جز اء سيئة (surat Yunus: 27), al-Razi berkata, ilmu adalah cahaya yang berasal dari Allah, maka setiap hati dapat menemukan ma'rifatullah dan ilmu tidak ditemukan dalam hati yang gelap. Al-Syibli mengumpamakan hal ini dalam syairnya: 19. لي بيت انت ساكنه غيرمحتاج الي السرج

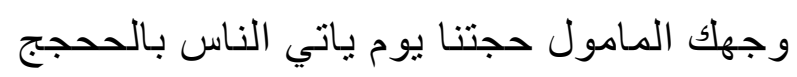

\section{E. Sikap al-Razi terhadap Cerita Isra'iliyat}

Al-Razi adalah salah seoarang mufassir yang mensucikan al-Qur'an dari cerita-cerita israiliyat dan mengingatkan agar menjauhinya karena bertentangan dengan akal dan naqli.20 Ia tidak menerima cerita-cerita israiliyat kecuali telah dikuatkan al-Qur'an dan khabar yang sahih. Contoh: menurut cerita israiliyat, tongkat Nabi Musa diambil dari syurga, mempunyai dua cabang, yang mampu menghilangkan kezaliman, ukurannya sepuluh kali tinggi dari Nabi Musa. Menurut al-Razi cerita ini wajib ditinggalkan karena tidak ada nash mutawatir yang menjelaskannya serta tidak sesuai dengan pengamalan atau fakta.

17Al-Umariy, op. cit., 127-128

18Ibid.

19Ibid., h. 131

20Muhammad Ibrahim, op. cit., h. 224 


\section{KESIMPULAN}

Berdasarkan uraian di atas, maka kesimpulan yang dapat dikemukakan adalah:

1. Al-Razi adalah seorang mufassir, filosof, teolog dan fuqaha. Beliau menguasai banyak disiplin ilmu pengetahuan, baik pengetahuan agama maupun umum. Kesemua ilmu tersebut digunakan dalam menafsirkan ayat-ayat al-Qur'an, sehingga tampak uraiannya terhadap suatu ayat sangat luas, meskipun kitab tafsirnya tidak sempat diselesaikan, yaitu hanya sampai pada surat al-Anbiya'.

2. Sebelum menafsirkan ayat-ayat al-Qur'an, beliau mengemukakan jumlah ayat dalam suatu surat yang akan dijelaskan, termasuk jumlah ayat-ayat Makkiyah dan Madaniyah di dalamnya. Kemudian beliau mengemukakan ayat yang akan dijelaskan, lalu ditafsirkannya dengan mengemas penjelasannya dalam bingkai فيه مسائل (di dalamnya ada beberapa masalah) dan sub masalah. Dalam kemasan uraian tersebut, al-Razi mengelaborasi semua pengetahuannya dalam menafsirkan ayat-ayat al-Qur'an.

3. Kitab tafsir Mafâtih al-Ghaib bercorak ra'yi (rasional), filosofis, ilmi, teologis dan fiqhi. Teologinya condong kepada Asy'ari dan fiqhinya condong kepada Syafi'i. Metodologinya adalah tahlily, ayat-ayat dijelaskan berdasarkan urutannya dalam Mushaf Usmani, berbagai aspek diuraikan di dalamnya, seperti bahasa, qira'at, munasabah, asbab nuzul, syair dan kaedah-kaedah ushul.

4. Sebagai seorang rasional, ia hanya mengutip sedikit hadis (terbatas) dan menghindari atau mensucikan al-Qur'an dari cerita-cerita isra'iliyat. Ia juga tidak mengakui adanya nasikh mansukh dalam al-Qur'an.

\section{DAFTAR PUSTAKA}

'Abd al-Rahman, Muhammad Ibrahim. Manhaj al-Fakhral-Razy fiy al-Tafsir. Mishr: alShadr Likhidmati ath-Thaba'ah, 1989

Al-Dzahabi, Muhammad Husayn. al-Tafsir wa al-Mufassirun. Jilid I Beirut: Dar al-Qalam, t.th.

Fakhr al-Din, Muhammad al-Razi. Tafsir al-Fakhr al-Razi.t.tp: Dar al-Fikr, t.th

Jibril,Muhammad al-Sayyid. Madkhal ila Manahij al-Mufassirin. Kairo: t.p, t.th

Muhammad Hasan Al-Umariy, Muhammad Hasan. al-Imam Fakhr al-Din al-Raziy. t.tp: tp, t.th.

Nashr, Sayyid Husayn. Fakhr al-Din al-Razi, dalam M.M. Syarif, "a History of Muslim Philosophy (td) 